\title{
GENDER AND ACHIEVEMENT-RELATED BELIEFS AMONG ENGINEERING STUDENTS
}

\author{
Gail D. Heyman," Bryn Martyna, and Sangeeta Bhatia \\ University of California, San Diego
}

\begin{abstract}
Achievement-related beliefs were examined among a group of 238 college students in engineering ( 38 female, 104 male) and nonengineering majors (57 female, 39 male) to understand why women enter engineering majors at a low rate and are more likely than men to leave such majors. The results indicated that (a) among the engineering majors, women were more likely than men to identify engineering aptitude as a fixed ability, a belief that was associated with a tendency to drop classes when faced with difficulty; (b) female engineering majors were more likely to perceive male and female engineering students as receiving different treatment than their male counterparts; and (c) female engineering majors tended to place more emphasis on extrinsic factors and less emphasis on intrinsic factors than female nonengineering majors, a pattern not seen among men. Implications for intervention programs are discussed.
\end{abstract}

\section{INTRODUCTION}

The proportion of women entering many traditionally male-dominated professions has increased substantially in recent years. However, gender ratios in the field of engineering have remained highly unbalanced in the United States, with women constituting only about $20 \%$ of engineering majors and holding only about $9 \%$ of engineering jobs (National Science Foundation, 2000). This situation contrasts with many other traditionally male-dominated professions, such as law and medicine. For example, in the 1999-2000 academic year, 45.8\% of entering medical students in the United States were female (Barzansky, Jonas, \& Etzel, 2000).

What might account for the gender imbalance in engineering? There can be little doubt that historical patterns of institutionalized gender discrimination play a key role. However, there is evidence that achievement-related beliefs are also involved (Eccles, 1987, 1994). This article examines beliefs that may be related to the differential entry and retention rates in engineering for women versus men. The beliefs of female engineering students were of central interest, and the beliefs of male engineering students and of male and female nonengineering students were examined for the purpose of comparison.

Three major types of beliefs were examined in this exploratory study: (a) beliefs about the nature of abilities and the meaning of difficulties that are encountered, (b) beliefs about

\footnotetext{
* Correspondence concerning this article should be addressed to Gail D. Heyman, Department of Psychology, University of California, San Diego, 9500 Gilman Drive, La Jolla, CA 92093-0109; e-mail: gheyman@ucsd.edu. This research was supported by National Institute of Child Health and Human Development Grant HD38529. We thank Brian Compton and Jessica Giles for helpful comments on an earlier version of this article.
} 
whether male and female engineering students are treated differently, and (c) values and interests. Each of these is described below.

\section{Beliefs About the Nature of Abilities and the Meaning of Difficulties}

Numerous research studies have suggested that individuals' conceptions of their own abilities (or efficacy) can have substantial implications for career-related choices (see Bandura, Barbaranelli, Caprara, \& Pastorelli, 2001). It is also possible that individuals' more general implicit beliefs about the nature of ability may have implications for these processes (see Dweck, 1999). As a first step in addressing this issue, one set of questions in the present study focused on how engineering and nonengineering students conceptualize intellectual abilities and how they interpret and respond to the academic difficulties they encounter. The key dimension of interest was whether individuals tend to view intelligence as being fixed or malleable (see Dweck, 1999). An individual with an entity (fixed) view of intelligence would be likely to agree that intelligence is an aspect of a person that cannot be changed. In contrast, someone with an incremental (malleable) view of intelligence would be likely to disagree with such statements. These views of intelligence have been linked to different motivational responses to challenging situations (Cain \& Dweck, 1995; Henderson \& Dweck, 1990; Leggett, 1985; see also Dweck, 1999; Stipek \& Gralinski, 1996) . For individuals who hold entity views of intelligence, difficulties are seen as potentially reflecting on enduring intellectual deficits. Consequently, difficulties tend to be associated with performance decrements and a failure to persist in the face of obstacles. In contrast, for individuals who hold incremental views of intelligence, difficulties tend to be viewed as less threatening, merely signaling a need for increased effort or a change in strategy.

Dweck (1999) argued that girls and women, particularly those of high ability, may be more likely than boys and men to develop entity views of ability and to view difficulties as aversive. One reason is that bright girls are especially likely to receive a great deal of global praise when they are young (see Dweck, 1999). This global praise can convey the implicit message that ability that can be readily assessed on the basis of performance outcomes (see also Kamins \& Dweck, 1999, and Mueller \& Dweck, 1998, regarding the paradoxical effects of praise). Such patterns may also lead high-ability girls and women to expect frequent praise. As a result, many become attracted to tasks in which they are confident of success. Consequently, they may "opt for easier programs of study, avoiding advanced math and science because these feel too risky" (Dweck, 1999, p. 124). Dweck also raised the possibility that bright girls and women are especially vulnerable to treating any outcome short of the highest grade as a failure (see also Bell, 1989). Consequently, when such women do not receive high grades, they may feel that it is time to consider whether they might be more successful in another major.

\section{Perceptions of Whether Gender Affects Treatment}

The second major set of questions in the present study concerned perceptions of the social climate faced by female engineering students, which has been identified as an important factor affecting women's persistence (Brainard \& Carlin, 1998; Davis 1996, Meinhodlt \& Murray, 1999; Seymour \&Hewitt, 1994; Solnick, 1995). The social climate may be especially important in a domain such as engineering, in which women face stereotype threat. Steele 
and Aronson (1995) defined stereotype threat as "being at risk for confirming as self-characteristic a negative stereotype about one's group" (p. 797). According to this view, it is not necessary for an individual to internalize a negative stereotype to experience stereotype threat; one need only be aware that he or she may be judged by others with reference to the stereotype (Steele, 1997). Even though women in engineering may perform well and have confidence in their skills, a situational stereotype threat may produce a fear of being linked to the negative stereotype about their group. The presence of a stereotype threat creates a recurrent need for individuals to disprove the stereotype as they progress to increasingly more advanced levels within a domain.

Might there be differences between male and female engineering students in the extent to which they perceive differential treatment on the basis of gender? Consistent with this possibility, Meinholdt and Murray (1999) found that in a sample composed primarily of engineering and science majors, male students tended to have relatively negative attitudes about women. For example, men were more likely than women to agree with the statement "men make better engineers than women." If women are in an environment in which they perceive differential treatment, but their male classmates do not, it might serve to increase the gender

divide between men and women. For example, in such a context, a woman may be reluctant to express her concerns about differential treatment from men because of the likelihood that her perspective will be discounted.

\section{Values and Interests}

The third set of exploratory questions focused on self-perceptions as they relate to achievement and achievement-related decisions. One question concerned whether male and female engineering students differ in the extent to which they see their interests as well matched to their chosen courses of study. Such questions of fit play an important role in many models of achievement motivation, such as expectancy-value models (Atkinson, 1966; Wigfield \& Eccles, 2000). Although there is evidence that men are more likely than women to view technical fields such as engineering to be a good fit with their interests (Benbow \& Minor, 1986; see Eccles, 1987, 1994), it is not clear that such factors play a role among female students who have chosen engineering from a range of available options (see Deaux, 1984, concerning evidence that among men and women engaged in the same activity, few gender differences are typically found).

A related issue is the role of personal values about careers and achievement. Previous research has suggested that values about the importance of different factors in one's career can have important implications for one's choice of an occupation (see Eccles, 1994). Of key interest in the present study was whether female engineering majors differ from nonengineering majors in their personal values about careers. Of particular interest were values emphasizing extrinsic factors, such as money and prestige, and intrinsic motivational factors, such as the enjoyment that comes from participating in an activity (see Lepper \& Henderlong, 2000). Also of interest were the value of a flexible work environment and the opportunity to make a contribution to society. Understanding whether women inside and outside of engineering differ in their perceptions of the importance of such factors may provide insights into what factors might facilitate the recruitment and retention of women in engineering. 


\section{METHOD}

\section{Participants}

Participants were 238 undergraduates enrolled at the University of California, San Diego. Among the 142 participants ( 38 female, 104 male) who were enrolled in an engineering program, 73 were in computer science and engineering (a major that combines computer science and engineering curricula), 26 were in bioengineering, 22 were in structural engineering, 11 were in mechanical engineering, 7 were in electrical engineering, and 3 were in other engineering majors. The reported ethnicities for this group are as follows: $47.2 \%$ White, $1.4 \%$ African American, 38.0\% Asian, 1.4\% Hispanic, and 4.2\% other; $7.7 \%$ did not report their ethnicities. Among the comparison group of 96 nonengineering majors ( 57 female, 39 male), 46 were social science majors, 28 were natural science majors, 17 were humanities majors, and 5 were in other nonengineering majors. The reported ethnicities for this group are as follows: 52.3\% White, 1.0\% African American, 22.9\% Asian, 8.3\% Hispanic, and 9.4\% other; 6.2\% did not report their ethnicities.

Participants were recruited with the assistance of faculty members across a range of disciplines. Participants filled out questionnaires in their classes.

\section{Measures}

Beliefs about the nature of abilities and the meaning of difficulties. To examine beliefs about the nature of an aptitude for engineering, participants were asked to rate their levels of agreement with the following two statements: (a) "You have a certain amount of aptitude for engineering, and you really can't do much to change it"; and (b) "You can learn new things, but you can't really change your basic aptitude for engineering." Participants rated their agreement on scales ranging from 1 (strongly agree) to 6 (strongly disagree). Consistent with other research examining entity and incremental beliefs (e.g., Levy \&Dweck, 1999) responses were averaged, and participants whose averages were above 3.5 (indicating a tendency to disagree with the statements) were classified as having an incremental theory of aptitude for engineering. Those whose average scores were below 3.5 were classified as having an entity theory of aptitude for engineering. Participants whose scores were exactly 3.5 were excluded from all analyses that included the entity-incremental distinction.

An analogous pair of questions was included to assess beliefs about general intelligence. These questions were identical, except that the phrase basic intelligence replaced the phrase aptitude for engineering. Responses were scored in the same way, with each participant being classified as having an incremental theory of intelligence or an entity theory of intelligence (except for those whose average responses were 3.5, who were excluded from all analyses that included this distinction).

To examine responses to difficulty, participants were asked to recall a time when they had difficulty in a college course and to describe the difficulty. They were asked to select from a set of forced-choice options to describe how they had responded to the difficulty: They dropped the class, worked less hard, worked about the same amount, or worked harder.

Perceptions of whether gender affects treatment. Two measures were used to examine students' perceptions of possible gender differences in how engineering students are treated. One measure asked students whether they believed that male and female students in their major were treated differently. The second measure asked students to rate their levels of agreement 
Table 1. Percentage of Participants Who Endorsed Entity Beliefs Concerning Engineering Aptitude and Intelligence, by Gender and Major

\begin{tabular}{lcccccc}
\hline & \multicolumn{2}{c}{ Women } & & \multicolumn{2}{c}{ Men } \\
\cline { 2 - 3 } \cline { 5 - 6 } & $\mathrm{E}$ & $\mathrm{NE}$ & & $\mathrm{E}$ & $\mathrm{NE}$ \\
Engineering aptitude & 72 & 38 & & 46 & 60 \\
Intelligence & 50 & 35 & & 46 & 45 \\
\hline
\end{tabular}

with the statement "The climate women face in engineering is no different from the climate faced by men." Participants rated their agreement on a forced-choice scale ranging from 1 (strongly agree) to 6 (strongly disagree).

Values and interests. To assess whether men and women in engineering differed in the extent to which they viewed their interests as being a good fit with their majors, they were asked, "To what extent do you think this major is a good match to your interests?" The scale ranged from 1 (not at all) to 5 (perfect).

To assess students' weighting of particular factors in their careers, they were instructed, "Rate the importance to your career of each of the following, from 1 (not at all important) to 5 (essential)." All categories for which multiple items were used were averaged to form a single scale. The following items assessed the importance of extrinsic factors: "making enough money to live comfortably," "the opportunity to make a large amount of money," and "a prestigious occupation." The following items assessed the importance of intrinsic factors: "working on interesting projects" and "the opportunity to learn new things." Additional items included "having a flexible schedule" and "making a contribution to society."

\section{RESULTS}

\section{Beliefs About the Nature of Abilities and the Interpretation of Difficulties}

One goal of the present research was to determine whether female engineering students would show a greater tendency than their male counterparts to endorse entity (fixed) views of engineering aptitude. This was indeed the case: Of participants who endorsed either entity or incremental beliefs (i.e., their scores were above or below 3.5, the midpoint of the scale), $72 \%$ of female engineering students were classified as holding entity theories of aptitude for engineering, as compared to $46 \%$ of male engineering students, $\chi^{2}(1, n=125)=6.28, p<.05$. In contrast, no such gender differences were seen concerning more general beliefs about intelligence, with both male and female engineering students endorsing entity views of intelligence about half of the time. Table 1 shows the percentage of participants who endorsed entity beliefs about engineering aptitude and intelligence by gender and major.

Of the women who reported dropping a class in the face of difficulty, $100 \%$ also endorsed entity beliefs about engineering aptitude. In contrast, among women who did not report drop- 
ping a class in the face of difficulty, $61 \%$ endorsed entity beliefs about engineering aptitude, $\chi^{2}(1, n=32)=4.90, p<.05$. No such relation between beliefs about engineering aptitude and having dropped a course in the face of difficulty was seen among the male engineering students. ${ }^{1}$

\section{Perceptions of Whether Gender Affects Treatment}

Another goal of the present study was to determine the extent to which women might perceive differences in how male and female engineering students are treated. Just over half (55\%) of female engineering majors perceived gender differences in how engineering students are treated, as compared to only about a quarter (27\%) of their male counterparts, $\chi^{2}(1, n=$ $137)=9.03, p<.005$. Among participants in nonengineering majors, only $12 \%$ of women and $17 \%$ of men said that men and women in their majors were treated differently, a difference that did not reach significance. This suggests that the gender differences in the perceived treatment of engineering students cannot be explained simply in terms of a general tendency for women to perceive differential treatment.

In a second measure of perceptions of differential treatment, participants were asked to rate their levels of agreement with the statement "The climate women face in engineering is no different from the climate faced by men" (on a scale ranging from 1 to 6 , with 6 indicating strong disagreement). Among engineering students, women $(M=4.44)$ were significantly more likely than men $(M=3.45)$ to disagree with this statement, $F(1,133)=10.32, M S E=$ 2.507, $p<.005$. Among nonengineering students, women $(M=4.48)$ were also more likely than men $(M=3.62)$ to disagree with this statement, $F(1,79)=8.131, M S E=1.694, p<.01$.

\section{Values and Interests}

Among engineering majors, women were less likely than men to report that engineering was a good match for their interests on a 5-point scale, $M$ for women $=3.58, M$ for men = 3.96, $F(1,139)=4.864, M S E=.771, p<.05$. One set of measures investigated whether the values and interests of female engineering students differed from those of women who had chosen nonengineering majors. Data from these measures are presented in Table 2. Two 2 (gender) $\times 2$ (major [engineering, nonengineering]) between-subjects analyses of variance were conducted to determine if there were any significant effects of gender or major on the personal values that were measured.

Measures of intrinsic values (see Table 1) revealed no main effects of gender or major. However, there was a significant gender-by-major interaction, with women in engineering showing less concern with intrinsic factors than women outside of engineering and the opposite

${ }^{1}$ One might wonder whether female students reported being more likely to drop a class in the face of difficulty as compared to their male counterparts because of a lack of academic preparedness. To evaluate this possible explanation, participants were asked to report their Scholastic Assessment Test (SAT) math scores and overall grade point averages. Analysis of these data revealed no evidence that reports of dropping a class were related to math ability or overall academic performance. However, SAT math scores did differ as a function of major and gender. Specifically, a 2 (gender [male, female]) $\times 2$ (major [engineering, nonengineering]) between-subjects analysis of variance confirmed that SAT math scores were higher for engineering students than for nonengineering students, as indicated by a significant main effect of major, $F(1,144)=14.9, M S E=4510, p<.001$. There was also a gender-bymajor interaction, $F(1,144), M S E=4510, p<.05$, with SAT math score showing a greater discrepancy across majors for women than for men. An analogous test of grade point average showed no effects of major or gender. 
Table 2. Mean Ratings of the Importance of Four Considerations to Participants' Choices of Careers, by Gender and Major

\begin{tabular}{lcccccc}
\hline & \multicolumn{2}{c}{ Women } & & \multicolumn{2}{c}{ Men } \\
\cline { 2 - 3 } \cline { 5 - 6 } & $\mathrm{E}$ & $\mathrm{NE}$ & & $\mathrm{E}$ & $\mathrm{NE}$ \\
Intrinsic interest & 4.20 & 4.53 & & 4.32 & 4.17 \\
Extrinsic interest & 3.63 & 3.26 & & 3.91 & 3.94 \\
Contributing to society & 3.50 & 4.24 & & 3.60 & 3.74 \\
Flexible schedule & 4.03 & 3.90 & & 3.78 & 3.74 \\
\hline
\end{tabular}

pattern seen for men, $F(1,231)=6.494, M S E=.433, p<.025$. These results suggest that women who place a high value on intrinsic factors may be relatively unlikely to select engineering as a major.

Measures of extrinsic value (money and prestige) revealed a different pattern. On this measure, there was a significant effect of gender, with men giving these factors higher ratings, $F(1,231)=17.061, M S E=5.427, p<.001$. This pattern was consistent with prior research showing that men tend to place higher value on money and prestige in their choices of careers (e.g., Tittle, 1982). There was a nearly significant interaction between major and gender, $F(1$, $231)=3.390, M S E=.603, p<.07$, with women in engineering giving greater weight to extrinsic factors (i.e., money and prestige) than women outside of engineering and men showing no difference related to major type.

The measure of the value of making a contribution to society revealed a significant effect of major, with engineering majors placing less weight on this value than others, $F(1,231)=$ $1.142, M S E=5.490, p<.01$. There was also a marginally significant interaction between major and gender, $F(1,231)=3.788, M S E=1.142, p<.07$, with women outside of engineering giving greater weight to making a contribution to society than men outside of engineering, but no clear difference between men and women in engineering. The measure of the value of a flexible schedule showed no significant effects.

\section{DISCUSSION}

The goal of the present research was to better understand the achievement-related beliefs of women in engineering, including beliefs about the nature of abilities, perceptions of whether male and female engineering students are treated differently, and values concerning achievement and career choices.

Questions measuring beliefs about the nature of abilities and the meaning of difficulties that are encountered suggest that female engineering students show a greater tendency than their male counterparts to endorse the belief that engineering aptitude is a fixed entity as opposed to something that develops over time. Among female engineering students, entity beliefs about engineering aptitude were associated with a tendency to drop a class when faced with difficulty. This finding is consistent with previous work suggesting that entity beliefs about ability tend to be associated with an unwillingness to persist in the face of obstacles (see 
Dweck, 1999; Henderson \& Dweck, 1990). A likely explanation for this result is that for women with entity views of engineering aptitude, difficulties tend to lead to an emphasis on evaluative concerns rather than strategies for improving outcomes in the future (see Dweck, 1999; Heyman \& Dweck, 1998). In contrast, for those with incremental views of engineering aptitude, obstacles may reflect on one's current level of skill but are unlikely to reflect on the potential for future success.

An additional issue for the present study concerned perceptions of differential treatment between men and women. The results indicated that among engineering students, over half of the women perceived differential treatment of men and women, as compared to just over a quarter of the men. There were no such gender differences in perceptions among the nonengineering students, and reports of differential treatment between men and women were less common. Participants' open-ended comments in response to this item suggest that the gender divide in perceptions of engineering students may be greater than the mere proportions of students who reported the presence of differential treatment might suggest. Specifically, some women made comments indicating that they were treated negatively by men, such as "[male students] tend to be condescending, others treat you like you don't know anything" and "sometimes we are not believed, looked down upon, seen as 'little girls." One female engineering student made a reference to "subtle intimidation by [male] students." In contrast, many men made comments suggesting that they believed that women were treated better than men, such as, "since female engineers are a rarity, there are usually better opportunities for them and they can get away with more than guys," "females are given more attention," and "professors are generally more understanding to women. Especially crying women." However, there were some men who described perceptions of more negative treatment for women. For example, one male engineering student commented, "It is really sad, but a lot of people treat women as though they were less intelligent."

Women in nonengineering majors were also likely to indicate that the climate in engineering is different for men than for women. For example, a female urban studies major commented that engineering is "a field of mostly males and I can imagine the amount of discrimination there is." She said that if she were in engineering,

people would think I was tagging along, the secretary, undependable because I'm an emotional woman or might flake out to have a family. I think all around I would not be taken seriously because I'm a girl and perceived as not having the drive or the right stuff.

Female engineering students face a social climate that contains negative stereotypes about women in technical fields and a widespread belief among their male classmates that female students are treated as well or even better than male students. This may produce a heightened awareness of how they are being judged in relation to the stereotypes. As a study participant noted, "as a female, I have to try extra hard to prove myself to male students and TA's that I do know material." The awareness that one is being judged in terms of a stereotype can be especially problematic when difficulties are encountered. For men, who do not face negative stereotypes about their aptitude for engineering, a difficult situation does not necessarily call their ability or belongingness to the domain to the forefront. However, for women, performance frustration on challenging tasks has the potential to confirm the possibility of stereotypical gender-based ability limitations or to lead to concerns that others will doubt their belongingness in the domain (Steele, 1997). Consequently, such women may be especially 
likely to view difficulty as a threat and to be distracted from engaging in the kinds of processes that are required to improve performance and enhance skills.

Why might female engineering students have been less likely than men to view engineering as a good fit with their interests? This may be because differences in orientations toward people and things (Dunteman, Wisenbaker, \& Taylor, 1978; Lippa, 1998) play a role even among students who have chosen engineering majors. If male engineering students frequently express their love of technology, as they often noted in their open-ended comments, it may raise questions of belongingness for women who do not share this enthusiasm.

It is notable that female engineering majors showed a different pattern of emphasis on intrinsic versus extrinsic factors than female nonengineering majors: Female engineering majors were more likely to emphasize extrinsic factors, including prestige, and were less likely to emphasize intrinsic factors, including the opportunity to work on interesting projects. In contrast, men showed no such tendencies toward such a pattern. These findings suggest that some women may decide to enter engineering because they are willing to sacrifice doing something in which have great interest in order to achieve the financial rewards and status associated with engineers, whereas men may not see this as a trade-off.

\section{Follow-Up Focus Group}

After obtaining these results, two of the authors presented a summary to a group of 14 female engineering students and led a discussion concerning these findings. Several students commented that they were concerned about what others would think if they asked "stupid" questions and were unwilling to ask questions in class unless they were convinced that they were good questions. In contrast, they felt that their male classmates did not share this concern. (One of the authors, who is an assistant professor of bioengineering, noted that in her 2 years of teaching, men have frequently asked questions, but no woman has ever asked a question.) During the session, one woman also commented that people often tell her how smart she must be to be in engineering. She said that it made her feel extra pressure, "that if I'm at the top I'm doing something wrong or doesn't belong. It's not ok to be a dumb girl in engineering, but you can be a dumb guy." These comments point to some interesting directions for future research on this topic.

\section{Limitations}

The limitations of the present study should be kept in mind when interpreting its results. A replication that includes more extensive measures and a sample that includes a greater number of female engineering majors would help establish the findings more definitively. Despite these limitations, it should be noted that the present study offers some conceptually meaningful, statistically significant results that are worthy of further investigation.

\section{Implications}

What are the implications of the present work for programs aimed at encouraging women to enter engineering majors and to complete their degree programs? The present research suggests that one component of an effective intervention program would be to teach women incremental beliefs about the field of engineering. Although the results of the present study 
do not indicate whether beliefs about engineering have a causal role in women's tendency to drop classes in the face of difficulties, previous work in which individuals have been taught to think in incremental ways has been effective in improving college performance (Aronson, Fried, \& Good, 2002; Wilson \& Linville, 1982, 1985; see also Hong, Chiu, Dweck, Lin, \& Wan, 1999, for related findings). Techniques for teaching such a view about engineering ability might include presentations by successful female engineering graduates focusing on obstacles they have faced and how they were able to overcome them.

The results of the present study also suggest that providing discussion forums for female engineering students might be useful in enhancing retention. Such forums might help women feel validated in their perceptions and exchange problem-solving strategies. It may also be useful to talk to women about their personal values and ways in which engineering may offer opportunities that are consistent with those values.

An early intervention that may prove useful would involve finding creative ways to encourage girls to become interested in how things work. For example, technology-related toys might be designed to appeal to girls and make them comfortable with taking things apart and putting them back together (see Kiesler, Sproull, \& Eccles, 1985, for related arguments concerning the use of computer games to build comfort and interest in working with computers more generally). In schools, an approach to understanding math, science, and technology with an emphasis on mastery rather than competition is likely to promote intrinsic motivation (Butler 1987; see Heyman \& Dweck, 1992), especially among women (Eccles, 1987). Female students might also be taught strategies to deal with potentially intimidating situations relating to technology, such as when others answer their questions using unfamiliar technical terms that they do not define. These efforts to promote girls' interest in engineering-related topics should help increase consideration of careers in engineering among women who place great emphasis on intrinsic factors when making achievement-related decisions. In addition, having more women in engineering who enjoy the work is likely to foster improved learning (see Cordova \& Lepper, 1996; Lepper \& Cordova, 1992).

Interventions may have a greater chance of success if they target men as well as women. If male engineering students were more interested in learning the perspectives of women, it could decrease tension between the genders. Such interventions would likely be most effective if conducted early in development, before sexist attitudes have a chance to become firmly ingrained.

A challenge in designing interventions will be to integrate efforts to change belief systems with efforts to change the broader social context, such as efforts to accommodate working parents (see Bellinger, 1996) and identify and decrease patterns of systematic discrimination (see Hopkins et al., 1999).

In conclusion, the present study builds on previous work suggesting that understanding social-cognitive factors such as beliefs about ability, perceptions of differential treatment, and personal values can offer insight into individuals' achievement-related choices.

\section{REFERENCES}

Aronson, J., Fried, C. B., \& Good, C. (2002). Reducing the effects of stereotype threat on African American college students by shaping theories of intelligence. Journal of Experimental Social Psychology, 38, 113-125. 
Atkinson, J. W. (1966). Motivational determinants of risk taking behavior. In J. W. Atkinson \& N. T. Feather (Eds.), A theory of achievement motivation (pp. 11-31). New York: John Wiley.

Bandura, A., Barbaranelli, C., Caprara, G. V., \& Pastorelli, C. (2001). Self-efficacy beliefs as shapers of children's aspirations and career trajectories. Child Development, 72, 187-206.

Barzansky, B., Jonas, H. S., \& Etzel, S. I. (2000). Educational programs in US medical schools, 1999-2000. Journal of the American Medical Association, 284, 1114-1120.

Bell, L. A. (1989). Something's wrong here and it's not me: Challenging the dilemmas that block girls' success. Journal for the Education of the Gifted, 12, 118-130.

Bellinger, R. (1996). Rigid male engineer culture adapts to times: Women lead TI transformation. Electronic Engineering Times, 924, 125.

Benbow, C. P., \& Minor, L. L. (1986). Mathematically talented males and females and achievement in the high school sciences. American Educational Research Journal, 23, 425-436.

Brainard, S., \& Carlin, L. (1998). A six year longitudinal study of undergraduate women in engineering and science. Journal of Engineering Education, 87, 369-375.

Butler, R. (1987). Task-involving and ego-involving properties of evaluative situations: The effect of different feedback situations on performance. Journal of Educational Psychology, 79, 474-482.

Cain, K. M., \& Dweck, C. S. (1995). The relation between motivational patterns and achievement cognitions through the elementary school years. Merrill-Palmer Quarterly, 41, 25-52.

Cordova, D., \& Lepper, M. R. (1996). Intrinsic motivation and the process of learning: Beneficial effects of contextualization, personalization, and choice. Journal of Educational Psychology, 88, $715-730$.

Davis, C. S. (1996). The equity equation: Fostering the advancement of women in the sciences, mathematics, and engineering. San Francisco: Jossey-Bass.

Deaux, K. (1984). From individual differences to social categories: Analysis of a decade's research on gender. American Psychologist, 39, 105-116.

Dunteman, G. H., Wisenbaker, J., \& Taylor, M. E. (1978). Race and sex differences in college science program participation. (Report to the National Science Foundation.) Research Triangle Park, NC: Research Triangle Institute.

Dweck, C. S. (1999). Self-theories: Their role in motivation, personality, and development. Philadelphia: Psychology Press/Taylor \& Francis.

Eccles, J. S. (1987). Gender roles and women's achievement-related decisions. Psychology of Women Quarterly, 11, 135-172.

Eccles, J. S. (1994). Understanding women's educational and occupational choices: Applying the Eccles et al. model of achievement related choices. Psychology of Women Quarterly, 18, 585-609.

Henderson, V., \& Dweck, C. S. (1990). Achievement and motivation in adolescence: A new model and data. In S. Feldman \& G. Elliott (Eds.), At the threshold: The developing adolescent (pp. 308-329). Cambridge, MA: Harvard University Press.

Heyman, G. D., \& Dweck, C. S. (1992). Achievement goals and intrinsic motivation: Their role in adaptive motivation. Motivation and Emotion, 16, 231-247.

Heyman, G. D., \& Dweck, C. S. (1998). Children's thinking about traits: Implications for judgments of the self and others. Child Development, 69, 392-403.

Hong, Y., Chiu, C., Dweck, C. S., Lin, D., \& Wan, W. (1999). Implicit theories, attributions, and coping: A meaning system approach. Journal of Personality and Social Psychology, 77, 588-599.

Hopkins N. et al. (1999). A study on the status of women faculty in science at MIT. MIT Faculty Newsletter, 9, 1-16.

Kamins, M. L., \& Dweck, C. S. (1999). Person vs. process praise and criticism: Implications for contingent self-worth and coping. Developmental Psychology, 35, 835-847.

Kiesler, S., Sproull, L., \& Eccles, J. S. (1985). Pool halls, chips, and war games: Women in the culture of computing. Psychology of Women Quarterly, 9, 451-462. 
Leggett, E. L. (1985, March). Children's entity and incremental theories of intelligence: Relationships to achievement behavior. Paper presented at the annual meeting of the Eastern Psychological Association, Boston.

Lepper, M. R., \& Cordova, D. (1992). A desire to be taught: Instructional consequences of intrinsic motivation. Motivation and Emotion, 16, 187-208.

Lepper, M. R., \& Henderlong, J. (2000). Turning "play” into “work” and “work” into "play": 25 years of research on intrinsic versus extrinsic motivation. In C. Sansone \& J. M. Harackiewicz (Eds.), Intrinsic and extrinsic motivation: The search for optimal motivation and performance (pp. 257-307). San Diego, CA: Academic Press.

Levy, S. R. \& Dweck, C. S. (1999). The impact of children's static versus dynamic conceptions of people on stereotype formation. Child Development, 70, 1163-1180.

Lippa, R. (1998). Gender-related differences and the structure of vocational interests: The importance of the people-things dimension. Journal of Personality and Social Psychology, 74, 996-1009.

Meinholdt, C., \& Murray, S. L. (1999). Why aren't there more women engineers? Journal of Women and Minorities in Science and Engineering, 5, 239-263.

Mueller, C. M., \& Dweck, C. S. (1998). Praise for intelligence can undermine children's motivation and performance. Journal of Personality and Social Psychology, 75, 33-52.

National Science Foundation. (2000). Women, minorities, and persons with disabilities in science and engineering: 2000. Arlington, VA: Author.

Seymour, E., \& Hewitt, N. (1994). Talking about leaving: Factors contributing to high attrition rates among science, mathematics, and engineering undergraduate majors. Boulder, CO: Bureau of Sociological Research.

Solnick, S. J. (1995). Changes in women's majors from entrance to graduation at women's and coeducational colleges. Industrial and Labor Relations Review, 48, 505-514.

Steele, C. M. (1997). A threat in the air: How stereotypes shape intellectual identity and performance. American Psychologist, 52, 613-629.

Steele, C. M., \& Aronson, J. (1995). Stereotype threat and the intellectual test performance of African Americans. Journal of Personality and Social Psychology, 69, 797-811.

Stipek, D. J., \& Gralinski, J. H. (1996). Children's beliefs about intelligence and school performance. Journal of Educational Psychology, 88, 397-407.

Tittle, C. K. (1982). Careers and family: Sex roles and adolescent life plans. Beverly Hills, CA: Sage.

Wigfield, A., \& Eccles, J. S. (2000). Expectancy-value theory of achievement motivation. Contemporary Educational Psychology, 25, 68-81.

Wilson, T. D., \& Linville, P. W. (1982). Improving the academic performance of college freshmen: Attribution therapy revisited. Journal of Personality and Social Psychology, 42, 367-376.

Wilson, T. D., \& Linville, P. W. (1985). Improving the performance of college freshmen with attributional techniques. Journal of Personality and Social Psychology, 49, 287-293. 